\title{
Safety and Systemic Exposure of Triamcinolone Acetonide Following Ultrasound-Guided Intra-Articular Injection of Triamcinolone Extended-Release or Standard Triamcinolone Acetonide in Patients with Shoulder Osteoarthritis: An Open-Label, Randomized Study
}

\author{
Peter Hanson ${ }^{1} \cdot$ Alan Kivitz $^{2}$ • Purvi Mehra ${ }^{3} \cdot$ Louis Kwong $^{4} \cdot$ Amy Cinar $^{5}$ • Joelle Lufkin ${ }^{5,6} \cdot$ Scott D. Kelley $^{5}$
}

Accepted: 11 May 2021 / Published online: 4 August 2021

(c) The Author(s) 2021

\begin{abstract}
Background and Objectives Osteoarthritis (OA) is a major public health burden. While knee and hip joints are most commonly affected, the glenohumoral (shoulder) joint is also frequently involved. We evaluated the pharmacokinetics and safety/ tolerability of triamcinolone acetonide extended-release (TA-ER) and triamcinolone acetonide crystalline suspension (TAcs) in patients with shoulder OA.

Methods In this phase 2, randomized, open-label, single-dose study (NCT03382262), adults with moderately-to-severely symptomatic shoulder OA for $\geq 6$ months randomly received a single ultrasound-guided intra-articular (IA) injection of TA-ER $32 \mathrm{mg}$ or TAcs $40 \mathrm{mg}$. Safety was evaluated throughout 12 weeks post-injection; blood samples for pharmacokinetic evaluations were collected pre-injection and through Day 85 post-injection.

Results Among 25 randomized patients, 12 received TA-ER and 13 received TAcs. Most patients were female (60\%), and all had moderate (72\%) or severe (28\%) shoulder OA. Adverse events (AEs) were reported by four (33\%) patients following TA-ER and three (23\%) following TAcs injection. No AE was serious or led to study discontinuation. Systemic exposure following TAcs was approximately 1.5-fold higher than that following TA-ER injection (geometric mean [GM] AUC 0 -last $873,543 \mathrm{vs} 557,602 \mathrm{~h} \times \mathrm{pg} / \mathrm{mL})$. GM $C_{\max }$ was also higher in TAcs- than TA-ER-treated patients (2034 vs $\left.1283 \mathrm{pg} / \mathrm{mL}\right)$. Bioequivalence testing confirmed lower systemic TA exposure following TA-ER than TAcs IA injection.

Conclusion These pharmacokinetic data confirm protracted release of TA from TA-ER following IA injection in patients with shoulder OA. Lower peak and systemic TA exposure following TA-ER suggests TA-ER could potentially confer an improved systemic safety profile over TAcs.
\end{abstract}

Trial Registration Number NCT03382262 (December 22, 2017 retrospectively registered).

Scott D. Kelley

sdkelley@bwh.harvard.edu

BioSolutions Clinical Research Center, La Mesa, CA, USA

2 Altoona Center for Clinical Research, Duncansville, PA, USA

3 ARTEMIS Institute for Clinical Research, San Diego, CA, USA

4 Harbor-UCLA Medical Center, Torrance, CA, USA

5 Flexion Therapeutics, Inc., Burlington, MA 01803, USA

6 Independent Consultant, Beverly, MA, USA

\section{Key Points}

In patients with moderate-to-severe shoulder OA who received a single IA injection, total and maximal exposure to TA when given as TA-ER was approximately two-thirds of that seen with TAcs.

By extending the period of time over which TA enters the synovium and thus diminishing total and peak plasma TA concentrations, TA-ER may be better tolerated than conventional formulations of TA. 


\section{Introduction}

Osteoarthritis (OA) is a major public health burden, with persistent pain as the most common and disabling symptom [1]. Estimates suggest that 250 million people worldwide may be affected. OA has a complex pathogenesis involving mechanical, inflammatory, and metabolic factors that collectively contribute to the deterioration and ultimate destruction of the synovial joint. Changes in cartilage composition render the cartilage surface prone to erosion from physical forces, leading to the proliferative and proinflammatory processes underlying joint damage [1]. While the knee and hip are the most commonly affected joints, the glenohumoral (shoulder) joint is also a common site of OA. Population-based studies suggest as many as $16-20 \%$ of adults aged $>65$ years may have some radiographic evidence of glenohumoral OA [2-4].

Guidelines regarding optimal management of shoulder $\mathrm{OA}$ are limited. General approaches to OA management are often employed, including applicable nonpharmacological methods, oral and intra-articular (IA) pain relief, and surgery in individuals with diminished functional status despite more conservative approaches [1, 5]. Pain relief with oral agents such as acetaminophen or nonsteroidal anti-inflammatory drugs may be suboptimal, and oral opioid and corticosteroid use carry significant safety risks $[1,5,6]$. As additional treatment options, intraarticular corticosteroids (IACS) can transiently suppress the hypothalamic-pituitary-adrenal axis and may lead to hyperglycemia in patients with diabetes [7] and increased intra-ocular pressure in patients with glaucoma. IA hyaluronic acids, while available in Europe, are not approved to treat shoulder OA in the USA.

Triamcinolone acetonide extended-release (TA-ER) is a poly(lactic-co-glycolic acid) (PLGA) microsphere-based formulation of TA approved in the USA for management of OA-related knee pain [8]. In clinical trials of patients with knee OA, TA-ER afforded clinically meaningful reductions in pain scores, with an acceptable tolerability profile, when compared with placebo or a standard TA crystalline suspension (TAcs) given as a conventional IA injection. Reductions in pain scores were maintained for up to 16 weeks in patients receiving a single injection of TA-ER and up to 48 weeks in those receiving 2 injections [9-12]. Given that the benefits associated with conventional IACS administration appear to be restricted to only several weeks following treatment [13], these studies suggest that pain-relief associated with IA TA-ER persists for appreciably longer than a single injection of traditional IACS. These observations are also supported by data from a phase 2 study in patients with knee OA showing prolonged bioavailability of TA-ER in the synovial fluid
(SF) compared with TAcs, with measurable synovial concentrations at 6-12 weeks following a single IA injection of TA-ER [14]. As reported by Kraus et al., TA released from the PLGA microspheres was present in the SF of patients with knee OA at 6 and 12 weeks after IA TA-ER, whereas, SF TA concentrations were undetectable in most patients at 6 weeks after IA TAcs [14]. As well, in patients receiving TA-ER, geometric mean (GM) SF TA concentrations peaked 1 week post-injection and then progressively declined to below the limit of quantification (BLOQ) for the assay at 16 weeks post-injection [14]. Interestingly, the GM maximum plasma TA concentrations $\left(C_{\max }\right)$ achieved $7 \mathrm{~h}$ post-IA injection of TA-ER $(967 \mathrm{pg} / \mathrm{mL})$ was approximately 11 -fold lower than that seen $6 \mathrm{~h}$ post-IA injection of TAcs $(11,065 \mathrm{~g} / \mathrm{mL})$. Thus, IA TA-ER prolonged SF joint residency and markedly lowered systemic TA exposure compared to IA TAcs [14].

The current study was undertaken to evaluate the pharmacokinetics (PK), safety and general tolerability following a single IA injection of TA-ER $32 \mathrm{mg}$ or TAcs $40 \mathrm{mg}$ in patients with shoulder OA.

\section{Methods}

This was a phase 2, randomized, open-label, single-dose study (NCT03382262). The study was conducted in compliance with current Good Clinical Practice and International Committee on Harmonisation Good Clinical Practice guidelines, and in accordance with the Declaration of Helsinki. The study protocol was approved by the Schulman Central Institutional Review Board, Cincinnati, OH, USA, prior to commencement of any study procedures. All patients provided written informed consent.

\subsection{Participants}

Adult male and female patients aged $\geq 40$ years with a body mass index $(\mathrm{BMI}) \leq 40 \mathrm{~kg} / \mathrm{m}^{2}$ and in good general health were enrolled. All patients were required to have symptomatic OA of the shoulder (the index joint) for $\geq 6$ months prior to screening and pain in the index joint for $>15$ days within the previous month. Shoulder OA was categorized based on radiologic findings as grade 2 (moderate: osteophytes 3-7 mm; with or without slight glenohumeral irregularity) or grade 3 (severe: osteophytes $>7 \mathrm{~mm}$, with or without glenohumeral joint space narrowing and sclerosis) according to the Samilson-Prieto Classification [15].

Patients with reactive, rheumatoid, or psoriatic arthritis, ankylosing spondylitis, or arthritis associated with inflammatory bowel disease were excluded. Exclusion criteria related to the index joint included past or current infection, crystal disease, fracture, surgery or arthroscopy, instability, 
dislocation, surgical hardware, or a history of full or partial rotator cuff tear. Patients were also excluded if they had IA treatment of any joint with a corticosteroid preparation or biologic agent within the previous 6 months; IA treatment of the index joint with hyaluronic acid within the previous 6 months; treatment with parenteral or oral corticosteroids within the previous 3 months; or had used inhaled, intranasal or topical corticosteroids within the previous 2 weeks.

\subsection{Study Design}

Patients were centrally randomized (1:1) to TA-ER $32 \mathrm{mg}$ administered as a single 5-mL IA injection or TAcs $40 \mathrm{mg}$ administered as a single 1-mL IA injection. TA-ER $(32 \mathrm{mg})$ was supplied as a sterile powder that was reconstituted in an isotonic, sterile aqueous solution of $\mathrm{NaCl}(0.9 \% \mathrm{w} / \mathrm{v})$, carboxymethylcellulose $(0.5 \% \mathrm{w} / \mathrm{v})$ and polysorbate- 80 $(0.1 \% \mathrm{w} / \mathrm{v})$. TAcs $\left(\right.$ Kenalog ${ }^{\circledR}-40$; triamcinolone acetonide injectable suspension, Bristol Myers Squibb, Princeton, NJ, USA) was administered as a sterile aqueous suspension with $\mathrm{NaCl}$ for isotonicity, carboxymethylcellulose sodium, and polysorbate-80. All injections were administered open-label through a 21-gauge (or larger) needle and guided by ultrasound using either a BK Mini Focus 1402, Phillips CX50, Digi-prince DP-6600, or a SonoSite M. Choice of numbing agent was based on standard-of-care, and the approach for injection (anterior, posterior, or lateral) was chosen by the injector. All patients were evaluated for 12 weeks postinjection. Blood samples for PK evaluation were collected at baseline (prior to injection); 1-6 (every hour), 8, 10, and $12 \mathrm{~h}$ post-injection; and 2, 3, 5, 8, 15, 22, 29, 57, and 85 days post-injection.

\subsection{Assessments}

Safety evaluations were based on treatment-emergent adverse events (AEs), physical exams, index shoulder assessments, vital signs, and routine clinical laboratory evaluations. All AEs were coded using Medical Dictionary for Regulatory Activities (MedDRA), Version 20.1.

Plasma TA concentrations were assayed with a validated liquid chromatography/tandem mass spectrometry method. Values BLOQ were identified as such. Concentrations that were undetectable were identified as "Not Detected" and recorded as BLOQ.

\subsection{Statistical Analysis}

All patients who received a full dose of study drug were included in the safety analyses. PK analyses included all patients in the safety population who received a full dose of study drug, completed scheduled sampling, and had sufficient plasma concentration data to allow calculation of
PK parameters. Plasma TA concentrations were assessed using non-compartmental analysis (Phoenix WinNonlin ${ }^{\mathrm{TM}}$ Version 8; Certara Corporation, Princeton, NJ, USA), and mean concentration profiles were calculated for each treatment arm. Descriptive statistics were calculated by time point for plasma TA concentrations. PK parameters included area under the plasma concentration-time curve from time 0 to $24 \mathrm{~h} \mathrm{AUC}_{0-24}$, AUC from time 0 to the last quantifiable plasma concentration $\mathrm{AUC}_{0-\text { last }}$, $\mathrm{AUC}$ from time 0 to infinity post-injection $\mathrm{AUC}_{0-\infty}$, drug clearance (CL), $C_{\text {max }}$, mean residence time $(M R T)$, half-life $\left(t_{1 / 2}\right)$, and time to maximum plasma concentration $\left(t_{\max }\right)$. AUC parameters were calculated using the linear trapezoidal method for ascending concentrations and the log trapezoidal method for descending concentrations.

Bioequivalence testing was conducted using the average bioequivalence method [16]. The natural log was used to transform values for the model, and $C_{\max }, \mathrm{AUC}_{0-24}$, and $\mathrm{AUC}_{0-\infty}$ PK parameters were exponentiated from a mixedeffects model. For each treatment group, GM (95\% confidence interval [CI]) $C_{\max }, \mathrm{AUC}_{0-24}, \mathrm{AUC}_{0-96}$, and $\mathrm{AUC}_{0-\infty}$ were determined. The assessment of bioequivalence was defined using a 90\% CI with lower and upper bounds of 0.80 and 1.25 , respectively.

Sample size calculations were based on the primary PK variables of $C_{\max }, \mathrm{AUC}_{0-t}$, and $\mathrm{AUC}_{0-\infty}$, assuming systemic TA exposure from TA-ER would not exceed that of the immediate-release TAcs formulation. A sample size of 12 patients in each treatment arm (assuming a 10\% drop-out rate) was estimated to provide approximately $90 \%$ power, with a two-sided alpha of 0.05 , to detect a ratio in the exposure PK parameter means (TA-ER/TAcs) of $<1.0$, with a pooled coefficient of variation estimate of 0.68 (PASS 15 Power Analysis and Sample Size Software [2017], NCSS, LLC. Kaysville, Utah, USA).

\section{Results}

\subsection{Patient Disposition and Baseline Characteristics}

The study enrolled and randomized 25 patients with shoulder OA to receive a single IA injection of TA-ER $(n=12)$ or TAcs $(n=13)$ (Fig. 1). The first patient was enrolled on December 4, 2017, and the last patient completed the study on October 9, 2018. All patients completed the study.

Baseline demographic and clinical characteristics were well-balanced across treatment groups (Table 1). Most patients were white $(n=21,84 \%)$ and a majority was female $(n=15,60 \%)$. On average, patients were 63 years of age with a BMI of $30 \mathrm{~kg} / \mathrm{m}^{2}$ at study outset. All patients had Samilson-Prieto Classifications of moderate $(n=18$, 
Fig. 1 Disposition of patients with symptomatic shoulder OA receiving single intra-articular injections of TA-ER (32 mg) or TAcs $(40 \mathrm{mg})$. OA osteoarthritis, TAcs triamcinolone acetonide crystalline suspension, $T A-E R$ triamcinolone acetonide extended-release

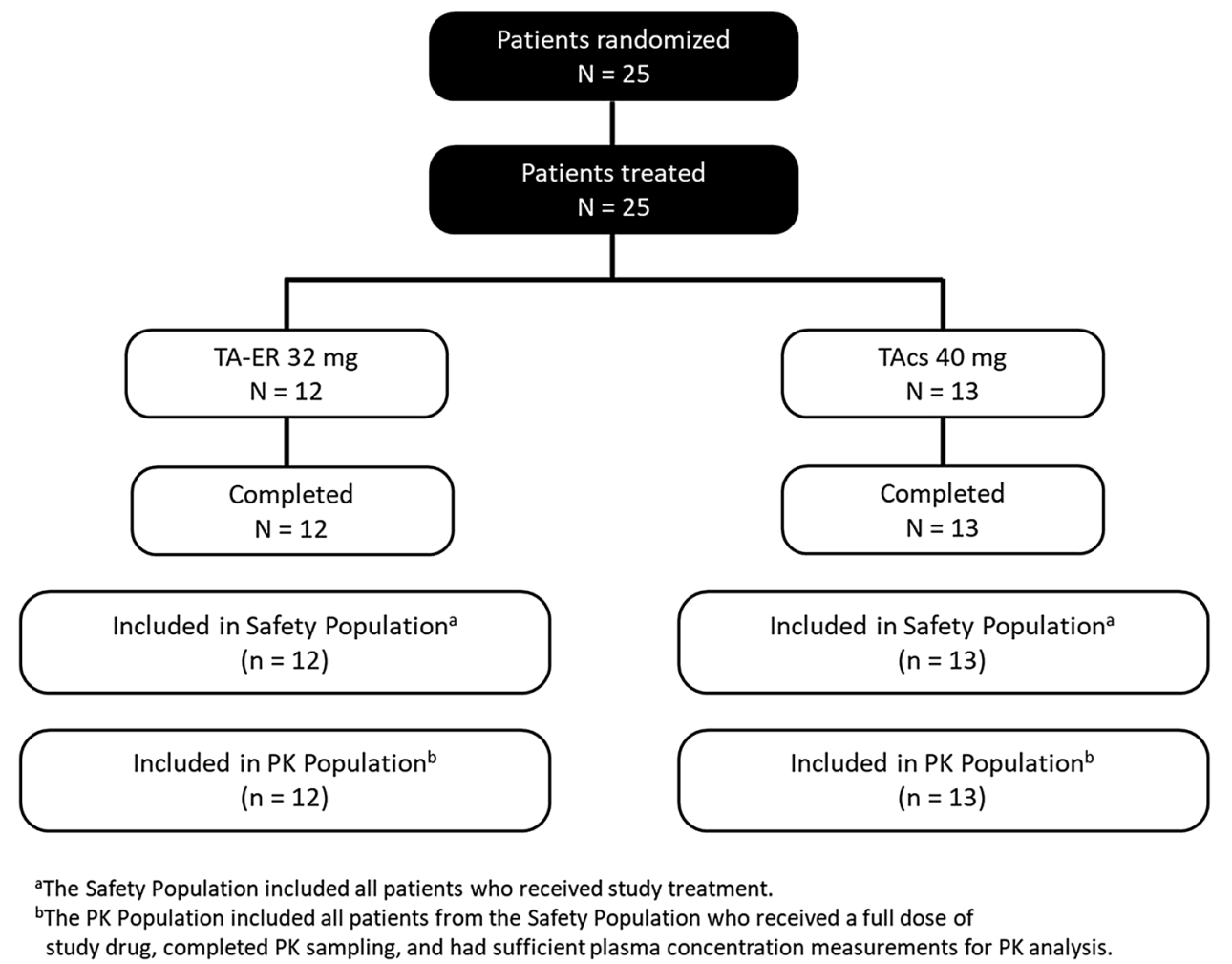

$72 \%)$ or severe ( $n=7,28 \%)$ shoulder OA, with a mean of 5 years separating initial diagnosis and study entry. The injection approach was very similar for both arms of the study with 9 posterior and 3 lateral injections for TA-ER compared with 9 posterior and 4 lateral injections for TAcs. No subanalyses based on patient demographics or injection approach were performed at this time due to small patient numbers in each subgroup. Fifteen patients $(60 \%)$ had received at least one $($ mean $=1.6)$ previous IA treatment of the index shoulder.

\subsection{Safety}

All AEs, reported by four patients (33\%) receiving TA-ER and three patients (23\%) receiving TAcs, were grade 2 or lower (Table 2). Most AEs were related to musculoskeletal or connective tissue disorders, including a decreased range of joint movement in one patient from each treatment group. The only other AE that occurred in more than one patient was nasopharyngitis, reported in two patients receiving TA-ER. A single AE (mild musculoskeletal discomfort) was considered related to study drug in a patient receiving TA-ER (this event was also considered related to the injection procedure). No AE was serious or led to patient discontinuing the study in either treatment group.

\subsection{Plasma Drug Concentrations}

Following an IA injection of TA-ER $32 \mathrm{mg}$, plasma concentrations of TA increased over the initial 4-h period, reaching a GM concentration of $1142 \mathrm{pg} / \mathrm{mL}$ (95\% CI, 823-1587) at $4 \mathrm{~h}$ post-injection. Thereafter, plasma TA concentrations declined slowly, reaching 904 pg/mL (95\% CI, 638-1281) at $12 \mathrm{~h}$ post-injection, $398 \mathrm{pg} / \mathrm{mL}$ (95\% CI, 287-550) at Day 15 , and $100 \mathrm{pg} / \mathrm{mL}$ (95\% CI, 54-185) at Day 85 (at which time 11 of 12 patients had measurable concentrations). In contrast, plasma TA concentrations following IA TAcs $40 \mathrm{mg}$ continued to increase through $6 \mathrm{~h}$ post-injection, when the GM concentration was $1690 \mathrm{pg} / \mathrm{mL}$ (95\% CI, 894-3195). Plasma concentrations remained at similarly high levels at Day $3(1413 \mathrm{pg} / \mathrm{mL}$; 95\% CI, 856-2332) and Day 5 (1038 pg/mL; 95\% CI, 724-1488) post-injection before declining steadily during the remainder of the study (Day 15: 723 pg/mL [95\% CI, 575-909]; Day 85: 131 pg/ $\mathrm{mL}$ [95\% CI, 64-269]).

\subsection{Pharmacokinetics}

Systemic exposure to TA was higher in patients receiving TAcs $40 \mathrm{mg}$ than in those receiving TA-ER $32 \mathrm{mg}$ (Fig. 2). The GM $C_{\max }$ was higher in patients receiving TAcs compared with those receiving TA-ER (2034 vs $1283 \mathrm{pg} / \mathrm{mL}$ ), 
Table 1 Baseline demographics and clinical characteristics of adult patients with symptomatic shoulder OA receiving single intra-articular injections of TA-ER (32 mg) or TAcs (40 mg)

\begin{tabular}{|c|c|c|c|}
\hline Parameter & $\begin{array}{l}\text { TA-ER } 32 \mathrm{mg} \\
(N=12)\end{array}$ & $\begin{array}{l}\text { TAcs } 40 \mathrm{mg} \\
(N=13)\end{array}$ & $\begin{array}{l}\text { Total } \\
(N=25)\end{array}$ \\
\hline \multicolumn{4}{|l|}{ Sex, $n(\%)$} \\
\hline Male & $3(25.0)$ & $7(53.8)$ & $10(40.0)$ \\
\hline Female & $9(75.0)$ & $6(46.2)$ & $15(60.0)$ \\
\hline \multicolumn{4}{|l|}{ Race, $n(\%)$} \\
\hline Black or African American & $1(8.3)$ & $2(15.4)$ & $3(12.0)$ \\
\hline White & $10(83.3)$ & $11(84.6)$ & $21(84.0)$ \\
\hline Other & $1(8.3)$ & 0 & $1(4.0)$ \\
\hline \multicolumn{4}{|l|}{ Ethnicity, $n(\%)$} \\
\hline Hispanic or Latino & $3(25.0)$ & 0 & $3(12.0)$ \\
\hline Not Hispanic or Latino & $9(75.0)$ & $13(100.0)$ & $22(88.0)$ \\
\hline \multicolumn{4}{|l|}{ Age (years) } \\
\hline Mean (SD) & $63.2(11.39)$ & $61.9(8.10)$ & $62.5(9.63)$ \\
\hline \multicolumn{4}{|l|}{ Body Mass Index, $n(\%)$} \\
\hline $18.5-24.9 \mathrm{~kg} / \mathrm{m}^{2}$ & $3(25.0)$ & $1(7.7)$ & $4(16.0)$ \\
\hline $25.0-29.9 \mathrm{~kg} / \mathrm{m}^{2}$ & $3(25.0)$ & $4(30.8)$ & $7(28.0)$ \\
\hline $30.0-34.9 \mathrm{~kg} / \mathrm{m}^{2}$ & $4(33.3)$ & $7(53.8)$ & $11(44.0)$ \\
\hline $35.0-39.9 \mathrm{~kg} / \mathrm{m}^{2}$ & $2(16.7)$ & $1(7.7)$ & $3(12.0)$ \\
\hline Mean (SD) & $28.9(5.98)$ & $30.7(3.59)$ & $29.8(4.86)$ \\
\hline \multicolumn{4}{|l|}{ Samilson-Prieto Classification Grade, $n(\%)$} \\
\hline Grade 0 , normal & 0 & 0 & 0 \\
\hline Grade 1, mild & 0 & 0 & 0 \\
\hline Grade 2 , moderate & $9(75.0)$ & $9(69.2)$ & $18(72.0)$ \\
\hline Grade 3 , severe & $3(25.0)$ & $4(30.8)$ & $7(28.0)$ \\
\hline \multicolumn{4}{|l|}{ Years Since Primary Diagnosis } \\
\hline Mean (SD) & $5.2(5.99)$ & $4.5(6.03)$ & $4.9(5.90)$ \\
\hline $\begin{array}{l}\text { Previous intra-articular treatment of index } \\
\text { shoulder, } n(\%)\end{array}$ & $6(50.0)$ & $9(69.2)$ & $15(60.0)$ \\
\hline
\end{tabular}

$O A$ osteoarthritis, $S D$ standard deviation, TAcs triamcinolone acetonide crystalline suspension, TA-ER triamcinolone acetonide extended-release and the median $t_{\max }$ was shorter for TAcs than TA-ER (4 vs 8 h) (Table 3). Systemic exposure was approximately 1.5fold higher with TAcs than TA-ER, both within 24-h postinjection (GM $\mathrm{AUC}_{0-24}$ of 36,076 vs $23,247 \mathrm{~h} \times \mathrm{pg} / \mathrm{mL}$ ) and through the time of the last quantifiable TA plasma concentration (GM $\mathrm{AUC}_{0-\text { last }}$ of 873,543 vs $\left.557,602 \mathrm{~h} \times \mathrm{pg} / \mathrm{mL}\right)$. The GM $t_{1 / 2}$ was $617 \mathrm{~h}$ in patients receiving TAcs and $569 \mathrm{~h}$ in those receiving TA-ER. These findings are consistent with slower liberation of TA into the systemic circulation from the synovial tissue following IA TA-ER injection. Although the total systemic exposure to TA was substantially higher in patients receiving TAcs than TA-ER, the duration of measurable plasma TA concentrations was similar following IA injection of TA-ER and TAcs (GM MRT of 839 and $832 \mathrm{~h}$, respectively).

\subsection{Bioequivalence}

Bioequivalence testing demonstrated that the systemic exposure to TA was not equivalent following IA administration of TA-ER $32 \mathrm{mg}$ or TAcs $40 \mathrm{mg}$ in the shoulder. Bioequivalence ratios (TA-ER/TAcs) were 0.63 (90\% CI, 0.36-1.09) for $C_{\max }, 0.64(0.37-1.11)$ for $\mathrm{AUC}_{0-24}, 0.65$ (0.40-1.05) for $\mathrm{AUC}_{0-96}$, and $0.59(0.43-0.81)$ for $\mathrm{AUC}_{0-\infty}$. Given the differential GMs of $C_{\max }, \mathrm{AUC}_{0-24}, \mathrm{AUC}_{0-96}$, and $\mathrm{AUC}_{0-\infty}$, the bioequivalence ratio point estimates, and that the upper boundary for the $90 \%$ CIs was below the test boundary of 0.80 , systemic exposure to TA following IA TA-ER in the shoulder was lower than that following IA TAcs.

\section{Discussion}

Data from the present study indicate that IA administration of TA-ER in the shoulder was well-tolerated and resulted in a TA PK profile similar to that reported following its IA administration to the knee. The study population was generally representative of patients with shoulder OA, comprising mainly female participants with moderate-to-severe shoulder 
Table 2 Safety and tolerability of single intra-articular injections of TA-ER $32 \mathrm{mg}$ or TAcs $40 \mathrm{mg}$ given to adult patients with symptomatic shoulder OA (safety population)

\begin{tabular}{|c|c|c|}
\hline & $\begin{array}{l}\text { TA-ER } 32 \mathrm{mg} \\
(N=12)\end{array}$ & $\begin{array}{l}\text { TAcs } 40 \mathrm{mg} \\
(N=13)\end{array}$ \\
\hline Any AE, $n(\%)$ & $4(33.3)$ & $3(23.1)$ \\
\hline Infections and infestations & $3(25.0)$ & 0 \\
\hline Nasopharyngitis & $2(16.7)$ & 0 \\
\hline Musculoskeletal and connective tissue disorders & $2(16.7)$ & $2(15.4)$ \\
\hline Joint range of motion decreased & $1(8.3)$ & $1(7.7)$ \\
\hline Musculoskeletal pain & 0 & $1(7.7)$ \\
\hline Osteoarthritis & 0 & $1(7.7)$ \\
\hline Serious AE $n(\%)$ & 0 & 0 \\
\hline AE leading to study discontinuation, $n(\%)$ & 0 & 0 \\
\hline \multicolumn{3}{|l|}{ AEs by maximum severity, $n(\%)$} \\
\hline Grade 1 & $2(16.7)$ & $2(15.4)$ \\
\hline Grade 2 & $2(16.7)$ & $1(7.7)$ \\
\hline Grades $3-5$ & 0 & 0 \\
\hline \multicolumn{3}{|l|}{ AEs by maximum relationship, $n(\%)$} \\
\hline Not Related & $3(25.0)$ & $3(23.1)$ \\
\hline Possibly, probably, or definitely related & $1(8.3)$ & 0 \\
\hline AE related to injection procedure, $n(\%)$ & $1(8.3)$ & 0 \\
\hline Index joint-related AE, $n(\%)$ & $2(16.7)$ & $1(7.7)$ \\
\hline Joint range of motion decreased & $1(8.3)$ & $1(7.7)$ \\
\hline Musculoskeletal discomfort & $1(8.3)$ & 0 \\
\hline Musculoskeletal pain & 0 & $1(7.7)$ \\
\hline \multicolumn{3}{|l|}{ Index joint-related AEs by maximum severity, $n(\%)$} \\
\hline Grade 1 & $2(16.7)$ & $1(7.7)$ \\
\hline Grades $2-5$ & 0 & 0 \\
\hline \multicolumn{3}{|c|}{ Index joint-related AEs by maximum relationship, $n(\%)$} \\
\hline Not related & $1(8.3)$ & $1(7.7)$ \\
\hline Possibly, probably, or definitely related & $1(8.3)$ & 0 \\
\hline
\end{tabular}

$A E$ treatment-emergent adverse event, TAcs triamcinolone acetonide crystalline suspension, TA-ER triamcinolone acetonide extended-release pain and relatively longstanding disease ( $~ 5$ years). In this population, a single IA injection of TA-ER was well-tolerated and demonstrated a safety profile comparable to TAcs. All AEs in the present study were mild or moderate in intensity, and most were related to musculoskeletal or connective tissue disorders. No AE was serious or led to patient discontinuation from study, and overall the safety profile of TA-ER was similar to that reported in phase 3 studies of patients with knee OA $[10,11]$.

Relative to IA TAcs, a single IA injection of TA-ER $32 \mathrm{mg}$ in the shoulder joint was associated with lower peak systemic TA levels and considerably reduced total systemic TA exposure. Specifically, the GM AUC $\mathrm{AU}_{0-24}$ and $\mathrm{AUC}_{0-96}$ values indicated an approximate 1.5 -fold higher TA systemic exposure following IA administration of TAcs compared with TA-ER, and bioequivalence testing confirmed lower TA systemic exposure following IA TA-ER $32 \mathrm{mg}$ than with IA TAcs $40 \mathrm{mg}$. These findings are consistent with the PK profile of TA following IA administration of TA-ER to the knee in patients with knee OA, i.e., the systemic GM $\mathrm{AUC}_{0-6 \text { weeks }}$ of TA was 6 times higher following a single IA injection of TAcs than a single injection of TA-ER [14]. These differences in systemic exposure, which could portend an improved systemic safety profile with TA-ER over TAcs are likely due to the differences in TA formulation. Whereas crystals of TA from the TAcs formulation completely dissolve in under $2 \mathrm{~h}$, less than $1 \%$ of the embedded TA is released from the TA-ER microsphere formulation during the same time period and under the same in vitro conditions [17].

The plasma TA concentration profile following TA-ER administration peaked at $4 \mathrm{~h}$ post-injection, was sustained over the ensuing $24 \mathrm{~h}$, and then declined slowly during the remainder of the study. This plasma concentration profile suggests that most of the TA remained embedded within the microspheres following IA administration, and was subsequently slowly released into the synovial fluid and absorbed 

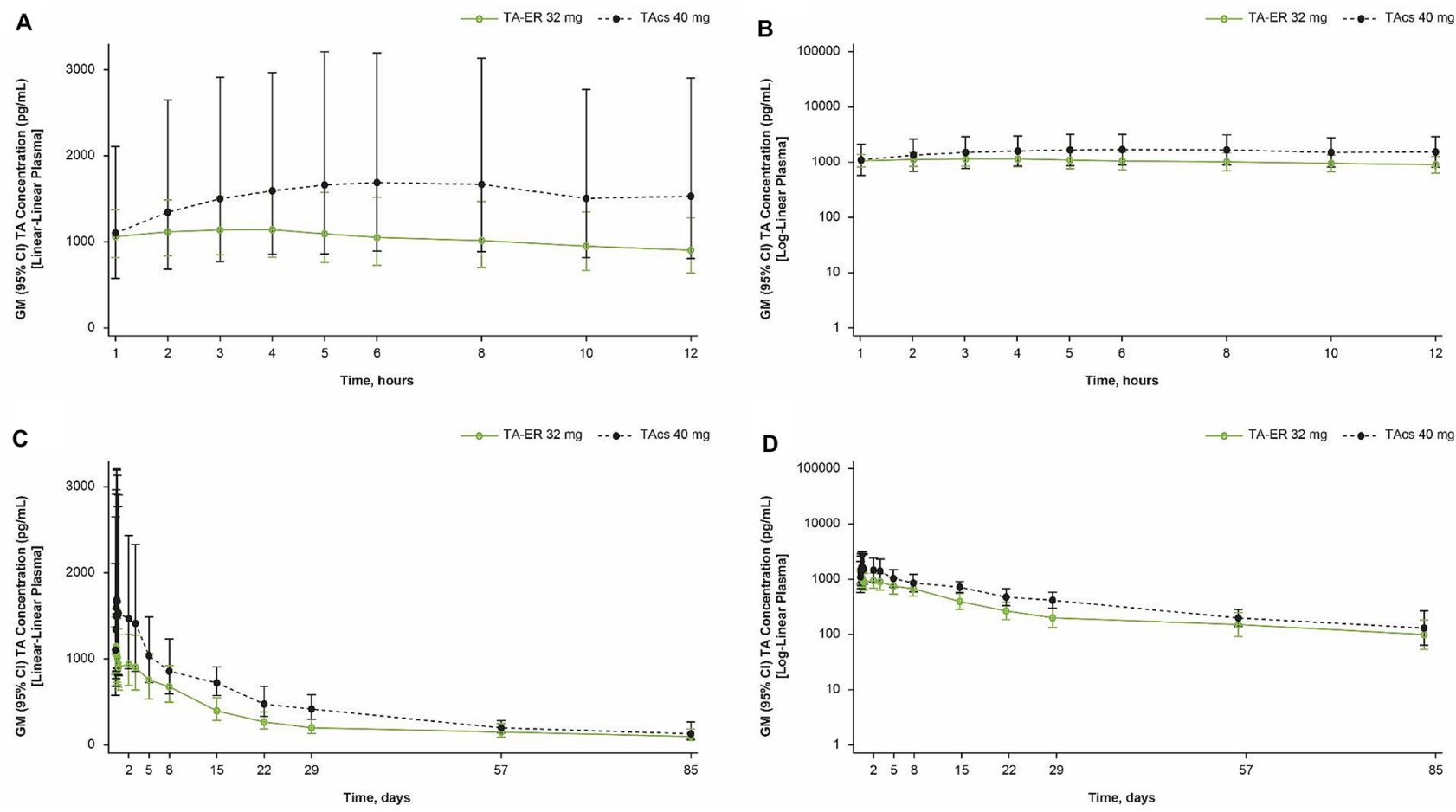

Fig. 2 Plasma TA concentration-time curves following single intraarticular injections of TA-ER $(32 \mathrm{mg})$ or TAcs $(40 \mathrm{mg})$ to the index joint of adult patients with symptomatic shoulder OA. Data are shown for the first $12 \mathrm{~h}(\mathbf{A}, \mathbf{B})$ and up to 85 days $(\mathbf{C}$ and $\mathbf{D})$ post-

injection expressed on linear $(\mathbf{A}, \mathbf{C})$ or logarithmic $(\mathbf{B}, \mathbf{D})$ scale. $C I$ confidence interval, $O A$ osteoarthritis, TAcs triamcinolone acetonide crystalline suspension, TA-ER triamcinolone acetonide extendedrelease

Table 3 Plasma TA pharmacokinetic parameters following intra-articular administration of TA-ER (32 mg) or TAcs (40 mg) to the index joint of adult patients with symptomatic shoulder OA (PK Population)

\begin{tabular}{lcccc}
\hline Parameter & $N$ & TA-ER $32 \mathrm{mg}$ & $N$ & TAcs $40 \mathrm{mg}$ \\
\hline$C_{\text {max }}, \mathrm{GM}(95 \% \mathrm{CI}), \mathrm{pg} / \mathrm{mL}$ & 12 & $1282.7(963.02-1708.38)$ & 13 & $2034.4(1098.17-3768.83)$ \\
$\mathrm{AUC}_{0-\mathrm{last}}, \mathrm{GM}(95 \% \mathrm{CI}), \mathrm{h} \times \mathrm{pg} / \mathrm{mL}$ & 12 & $557,602.1(427,051.32-728,062.54)$ & 13 & $873,543.2(615,704.94-1,239,356.10)$ \\
$\mathrm{AUC}_{0-24}, \mathrm{GM}(95 \% \mathrm{CI}), \mathrm{h} \times \mathrm{pg} / \mathrm{mL}$ & 12 & $23,246.5(16,825.70-32,117.57)$ & 13 & $36,075.6(19,736.15-65,942.40)$ \\
$\mathrm{AUC}_{0-96}, \mathrm{GM}(95 \% \mathrm{CI}), \mathrm{h} \times \mathrm{pg} / \mathrm{mL}$ & 12 & $85,740.3(62,183.45-118,221.04)$ & 13 & $132,648.4(79,655.23-220,896.80)$ \\
$\mathrm{AUC}_{0-\infty}, \mathrm{GM}(95 \% \mathrm{CI}), \mathrm{h} \times \mathrm{pg} / \mathrm{mL}$ & 11 & $625,590.9(461,835.32-847,410.32)$ & 11 & $1,061,253.7(811,387.53-1,388,065.85)$ \\
$t_{\text {max }}$, median $($ range $), \mathrm{h}$ & 12 & $4(1-57)$ & 13 & $8(2-1973)$ \\
$t_{(1 / 2)}$ median (range), h & 11 & $613(287-1026)$ & 11 & $676(267-1187)$ \\
$\mathrm{CL}, \mathrm{GM}(95 \% \mathrm{CI}), \mathrm{h} \times \mathrm{mL} / \mathrm{kg}$ & 11 & $51.2(37.76-69.29)$ & 11 & $37.7(28.82-49.30)$ \\
MRT, GM $(95 \% \mathrm{CI}), \mathrm{h}$ & 11 & $838.6(622.51-1129.58)$ & 11 & $832.4(635.60-1090.16)$ \\
\hline
\end{tabular}

$A U C$ area under the plasma concentration-time curve, $C I$ confidence interval, $C L$ drug clearance, $C_{\max }$ maximum plasma concentration, $G M$ geometric mean, $M R T$ mean residence time, TAcs triamcinolone acetonide crystalline suspension, $T A-E R$ triamcinolone acetonide extended-release, $t_{1 / 2}$ half-life, $t_{\max }$ time to maximum plasma concentration.

into the systemic circulation over a protracted period. This is also consistent with data from patients with knee OA, in whom SF TA concentrations remained detectable at 12 weeks after IA TA-ER but were largely undetectable at 6 weeks following IA TAcs [14]. Collectively, these data suggest TA-ER has the potential to sustain suppression of synovitis and prolong pain relief in patients with shoulder OA.
TA-ER is available in the USA for the management of OA pain of the knee [8]. In clinical trials of patients with knee OA, a single IA injection of TA-ER in the knee was associated with a significant reduction in pain and improvements in measures of quality of life, stiffness, and physical function up to 3 months after treatment [9-11]. The safety and tolerability profile in these studies was generally similar 
across patients receiving TA-ER, TAcs, or placebo. Finally, results of a double-blind randomized study in patients with type 2 diabetes mellitus and knee OA showed changes in blood glucose levels, as detected using continuous glucose monitoring, were significantly lower following IA TA-ER than following IA TAcs over the 3-day post-injection period $(14.7$ vs $33.9 \mathrm{mg} / \mathrm{dL}$, least-squares-mean difference [95\% $\mathrm{CI}]:-19.2[-38.0,-0.4] ; P=0.04)$. Furthermore, the percentage of time that glucose levels were in the target glycemic range $(70-180 \mathrm{mg} / \mathrm{dL})$ was numerically greater for TA-ER than for TAcs (63\% vs 50\%) [18]. These data suggest IA administration of TA-ER in patients with type 2 diabetes mellitus is associated with minimal disruption of blood glucose levels and thus may contribute to an improved safety profile compared with TAcs in this population.

Due to the complexity of shoulder conditions, the source of shoulder pain in OA is not always immediately apparent. A detailed history, physical examination, and appropriate imaging of the shoulder are required to determine the best course of management in each patient.

Limitations of the present study include the relatively small sample size and the open-label administration of study treatments. However, findings reported herein derived from patients with shoulder OA closely mirror those of previous studies in patients with knee OA [11, 14].

\section{Conclusion}

Results of this phase 2 study confirm an extended-release PK profile of TA-ER following IA administration in patients with shoulder OA. The overall lower systemic exposure of TA-ER $32 \mathrm{mg}$ suggests that it may confer an improved systemic safety profile relative to TAcs $40 \mathrm{mg}$. Data from this study are also consistent with the extended release and persistence of TA within the SF following TA-ER administration which may enable sustained analgesic effect within the glenohumeral joint. Taken together with studies that have demonstrated prolonged analgesic effects following IA TA-ER in patients with knee OA [9, 10], our results suggest that a larger phase 3 study is warranted to assess efficacy and safety of TA-ER in patients with shoulder OA pain.

Acknowledgements Professional medical writing and editorial assistance in the preparation of this article was provided by Holly Tomlin, MS, Flexion Therapeutics, Inc., and Tim Ibbotson, ApotheCom, Yardley, PA, and was funded by Flexion Therapeutics, Inc.

\section{Declarations}

Funding Flexion Therapeutics, Inc. funded this study.

Conflicts of interest Peter Hanson is an employee of BioSolutions Clinical Research Center; is a paid consultant for Centrexion and Flex- ion Therapeutics, Inc.; and has received research support from Centrexion, Flexion, and Samumed. Alan Kivitz serves on advisory committees or review panels for AbbVie, Boehringer Ingelheim, Genzyme, Janssen, Pfizer, Regeneron, Sanofi, and UCB; has received compensation for speaking and teaching from Celgene, Flexion Therapeutics, Inc., Genzyme, Horizon, Merck, Novartis, Pfizer, and Sanofi; serves as a paid consultant for Amgen, Gilead, Pfizer, Regeneron, Sanofi, and Sun Pharma Advanced Research; holds stock in Pfizer, Regeneron, and Sanofi; and serves on a steering committee for Flexion. Purvi Mehra is an employee of ARTEMIS Institute for Clinical Research, a clinical research firm with clients in the pharmaceutical and medical device industries. Louis Kwong reports no conflicts of interest. Amy Cinar is an employee of Flexion Therapeutics, Inc. and owns stock/stock options in Flexion. Joelle Lufkin was an independent consultant for Flexion Therapeutics, Inc. at the time the study was conducted and owns stock in Flexion Therapeutics, Inc. Scott D. Kelley was an employee of Flexion Therapeutics, Inc. at the time the study was conducted and owns stock in Flexion Therapeutics, Inc.

Ethics approval All patients provided written informed consent prior to the conduct of any study-related procedures.

Consent Not applicable.

Availability of data and material The data underlying the current report are not publicly available because of confidentiality restraints, but are available from the corresponding author on reasonable request.

Author contributions AC, JL, and SDK contributed to the study design and data analysis. PH, AK, PM, and LK were involved in data collection. All authors contributed to data interpretation. The first draft of the manuscript was prepared by Holly Tomlin, and all authors substantively reviewed subsequent drafts and approved the final version of the manuscript.

Code availability Not applicable.

Consent to participate All patients provided written consent.

Consent for publication Not applicable.

Open Access This article is licensed under a Creative Commons Attribution-NonCommercial 4.0 International License, which permits any non-commercial use, sharing, adaptation, distribution and reproduction in any medium or format, as long as you give appropriate credit to the original author(s) and the source, provide a link to the Creative Commons licence, and indicate if changes were made. The images or other third party material in this article are included in the article's Creative Commons licence, unless indicated otherwise in a credit line to the material. If material is not included in the article's Creative Commons licence and your intended use is not permitted by statutory regulation or exceeds the permitted use, you will need to obtain permission directly from the copyright holder. To view a copy of this licence, visit http://creativecommons.org/licenses/by-nc/4.0/.

\section{References}

1. Hunter DJ, Bierma-Zeinstra S. Osteoarthritis. Lancet. 2019;393:1745-59.

2. Zhang Y, Jordan JM. Epidemiology of osteoarthritis. Clin Geriatr Med. 2010;26:355-69. 
3. Kobayashi T, Takagishi K, Shitara H, Ichinose T, Shimoyama D, Yamamoto A, et al. Prevalence of and risk factors for shoulder osteoarthritis in Japanese middle-aged and elderly populations. J Shoulder Elbow Surg. 2014;23:613-9.

4. Oh JH, Chung SW, Oh CH, Kim SH, Park SJ, Kim KW, et al. The prevalence of shoulder osteoarthritis in the elderly Korean population: association with risk factors and function. J Shoulder Elbow Surg. 2011;20:756-63.

5. Ansok CB, Muh SJ. Optimal management of glenohumeral osteoarthritis. Ortho Res Rev. 2018;10:9-18.

6. Krebs EE, Gravely A, Nugent S, Jensen AC, DeRonne B, Goldsmith ES, et al. Effect of opioid vs nonopioid medications on pain-related function in patients with chronic back pain or hip or knee osteoarthritis pain: the SPACE randomized Clinical Trial. JAMA. 2018;319:872-82.

7. Oo WM, Liu X, Hunter DJ. Pharmacodynamics, efficacy, safety and administration of intra-articular therapies for knee osteoarthritis. Expert Opin Drug Metab Toxicol. 2019;15:1021-32.

8. ZILRETTA $^{\circledR}$ (triamcinolone acetonide extended-release injectable suspension), for intra-articular use. Burlington, MA: Flexion Therapeutics, Inc.; 05/2018.

9. Conaghan PG, Cohen SB, Berenbaum F, Lufkin J, Johnson JR, Bodick N. Brief Report: A phase IIb trial of a novel extendedrelease microsphere formulation of triamcinolone acetonide for intraarticular injection in knee osteoarthritis. Arthritis Rheumatol. 2018;70:204-11.

10. Conaghan PG, Hunter DJ, Cohen SB, Kraus VB, Berenbaum F, Lieberman JR, et al. Effects of a single intra-articular injection of a microsphere formulation of triamcinolone acetonide on knee osteoarthritis pain: a double-blinded, randomized, placebo-controlled, multinational study. J Bone Jt Surg Am. 2018;100:666-77.

11. Bodick N, Lufkin J, Willwerth C, Kumar A, Bolognese J, Schoonmaker C, et al. An intra-articular, extended-release formulation of triamcinolone acetonide prolongs and amplifies analgesic effect in patients with osteoarthritis of the knee: a randomized clinical trial. J Bone Jt Surg Am. 2015;97:877-88.
12. Spitzer AI, Richmond JC, Kraus VB, Gomoll A, Jones DG, Huffman KM, et al. Safety and efficacy of repeat administration of triamcinolone acetonide extended-release in osteoarthritis of the knee: a phase $3 \mathrm{~b}$, open-label study. Rheumatol Ther. 2019;6:109-24.

13. American Academy of Orthopaedic Surgeons (AAOS). Treatment of Osteoarthritis of the Knee Evidence-Based Guideline 2nd Edition. 2013. https://www.aaos.org/globalassets/quality-and-pract ice-resources/osteoarthritis-of-the-knee/osteoarthritis-of-theknee-2nd-editiion-clinical-practice-guideline.pdf. Accessed 3 June 2021.

14. Kraus VB, Conaghan PG, Aazami HA, Mehra P, Kivitz AJ, Lufkin $\mathrm{JJ}$, et al. Synovial and systemic pharmacokinetics (PK) of triamcinolone acetonide (TA) following intra-articular (IA) injection of an extended-release microsphere-based formulation (FX006) or standard crystalline suspension in patients with knee osteoarthritis (OA). Osteoarthr Cartil. 2018;26:34-42.

15. Elsharkawi M, Cakir B, Reichel H, Kappe T. Reliability of radiologic glenohumeral osteoarthritis classifications. J Shoulder Elbow Surg. 2013;22:1063-7.

16. United States Department of Health and Human Services. Guidance for Industry: Bioequivalence Studies with Pharmacokinetic Endpoints for Drugs Submitted Under an ANDA. 2013. https:// www.fda.gov/media/87219/download. Accessed 3 June 2021.

17. Tipnis NP, Shen J, Jackson D, Leblanc D, Burgess DJ. Flowthrough cell-based in vitro release method for triamcinolone acetonide poly (lactic-co-glycolic) acid microspheres. Int J Pharm. 2020;579:119130.

18. Russell SJ, Sala R, Conaghan PG, Habib G, Vo Q, Manning R, et al. Triamcinolone acetonide extended-release in patients with osteoarthritis and type 2 diabetes: a randomized, phase 2 study. Rheumatology (Oxford). 2018;57:2235-41. 